\title{
What is the Relation of Normal Blood Oxygen level with Tooth Decay?
}

\section{Muhammad Imran Qadir and Yasmeen Mureed*}

Institute of Molecular Biology and Biotechnology, Bahauddin Zakariya University, Multan, Pakistan

*Corresponding Author: Yasmeen Mureed, Institute of Molecular Biology and Biotechnology, Bahauddin Zakariya University, Multan, Pakistan.

Received: May 24, 2019; Published: July 03, 2019

DOI: $10.31080 /$ ASMI.2019.02.0291

\begin{abstract}
Blood oxygen level in the body can be determined by an instrument known as pulse oximeter. In blood oxygen level normal arterial oxygen level ranges from 75 to $100 \mathrm{~mm}$ of mercury. If the values are lower than the $60 \mathrm{~mm}$ of mercury then this usually indicates the need of the oxygen in the body. There are two methods of measuring the blood oxygen level in the body. Tooth decay is the destruction of the teeth. In this the upper protective layer of the teeth is destroyed by the action of the bacteria. Objective of present study was to co relate the blood oxygen level to the tooth decay [1]. A total of 200 students from Bahauddin Zakariya University of Multan, Pakistan participated in this study. We designed a project in this we asked from different subjects about their peripheral oxygen level and then evaluate the effect of peripheral oxygen level with tooth decay in different subjects.
\end{abstract}

Keywords: Pulse Oximeter; Dental Caries; Bacteria

\section{Introduction}

In blood oxygen level normal arterial oxygen level ranges from 75 to $100 \mathrm{~mm}$ of mercury. If the values are lower than the 60 then this usually indicates the need of the oxygen. Pulse rate is usually checked by the oximeter. Normal pulse rate is usually ranges from the 95 to $100 \%$. If Values are under of $90 \%$ then they are considered as low pulse rate. In this it sends the infrared rays to the capillaries in the finger and then it detects the how much light is reflected off the gases. And then reading indicates that how much blood is saturated. There are two methods of measuring the blood oxygen level in the body. One is the ABG method and the other method is the COPD method. In the ABG method, this test is used for the measurement of oxygen level in the body. And the second method is also used for the same purpose [2].

Tooth decay is the destruction of the teeth. In this the upper protective layer of the teeth is destroyed by the action of the bacteria. The destruction of the teeth is due to the overuse of the sugary material. This is common in all types of individual but especially in children. In this case a hole is formed between the teeth and this hole is known as cavity. In this Objective of present study was to co relate the blood oxygen level to the tooth decay.

\section{Material and Method}

A total of 200 students from Bahauddin Zakariya University of Multan, Pakistan participated in this study.

\section{Peripheral saturation of oxygen measurement}

Peripheral saturation of oxygen in the blood can be determined by an instrument known as pulse oximeter. The formula for the peripheral saturation of oxygen measurement is,

$$
\mathrm{SpO}_{2}=\mathrm{HbO}_{2} / \mathrm{HbO}_{2}+\mathrm{Hb}
$$

$\mathrm{HbO}_{2}=$ It is oxygenated heamoglobin

$\mathrm{Hb}=\mathrm{It}$ indicates that Deoxygenated heamoglobin

\section{Project designing}

We designed a project in this we asked from different subjects about their peripheral oxygen level and then evaluate the effect of peripheral oxygen level with tooth decay in different subjects.

\section{Statistical analysis}

Statistical analysis was applied by using MS- Software to calculate the results. In this t-Test applied to calculate the result. And the $\mathrm{p}<0.05$ is considered as significant value and it is represented by *known as stearic.

\section{Result and Discussion}

In this study t-test was applied and the results are calculated by this test. These results showed that there is a great effect of the normal blood oxygen level upon the tooth decay. The results were obtained were significant. The p-value for the females were obtained were 0.04 . The $p$-values for the males were 0.283 . While results that were obtained for the both males and females were 
0.358. So these values were considered as significant values. The results for the males and females are given in the table and in the graphical form [3-8].

\begin{tabular}{|l|c|c|c|}
\hline Gender & $\begin{array}{c}\text { Have tooth } \\
\text { decay }\end{array}$ & $\begin{array}{c}\text { Have no tooth } \\
\text { decay }\end{array}$ & P-value \\
\hline Males & $95.315 \pm 6.529$ & $97.075 \pm 3.626$ & 0.283 \\
\hline Females & $97.076 \pm 3.444$ & $95.191 \pm 12.2368^{*}$ & 0.04 \\
\hline Combined & $96.5 \pm 4,695$ & $95.717 \pm 6.86$ & 0.358 \\
\hline
\end{tabular}

Table 1: Relation of normal blood oxygen $($ Mean \pm SD) with tooth decay.

${ }^{*} \mathrm{P}<0.05$

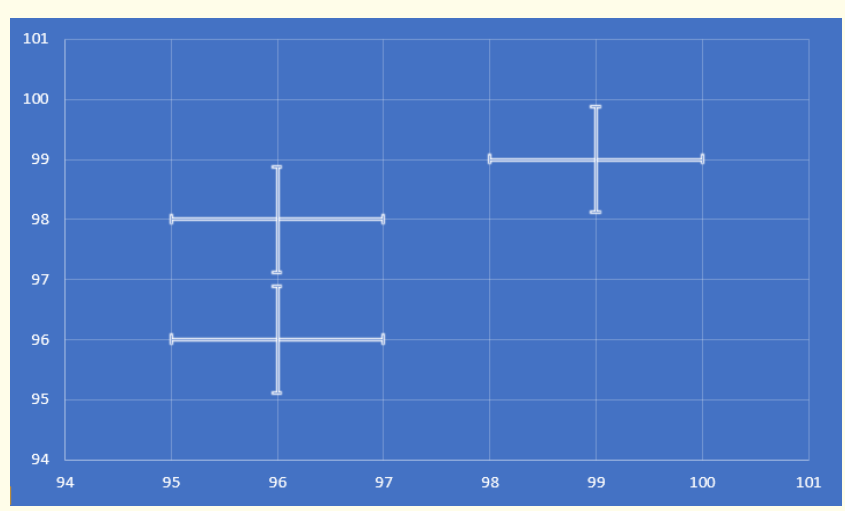

Figure 1: Relation of tooth decay with normal blood oxygen level in males.

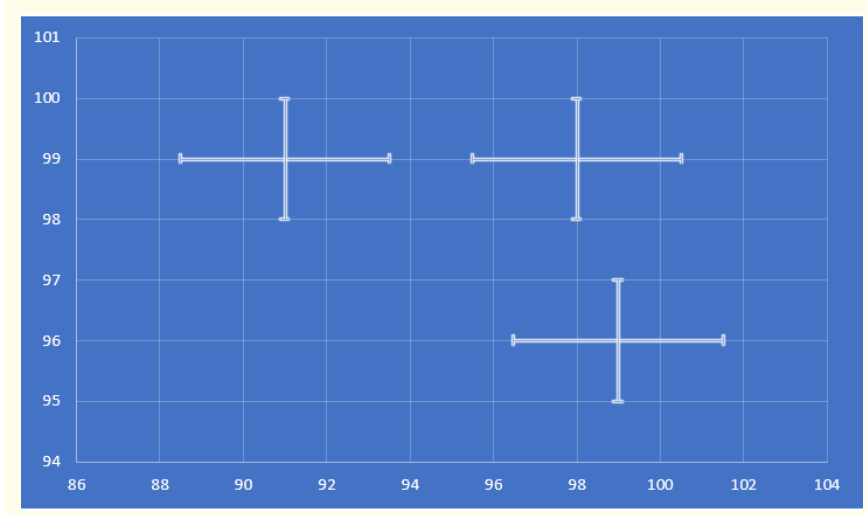

Figure 2: Relation of tooth decay with normal oxygen level in females.

\section{Conclusion}

Results are significant because the values are $\mathrm{P}<0.05$. So it indicates that there is relation between the normal blood oxygen level and the tooth decay.

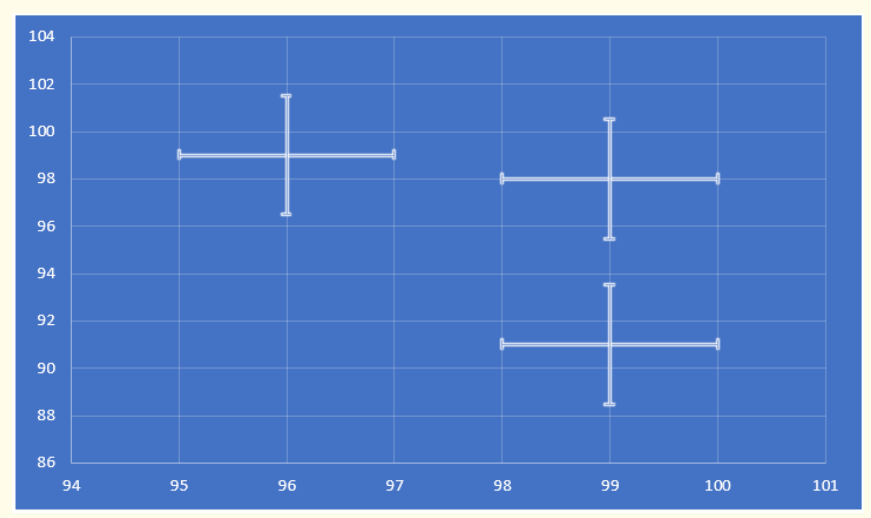

Figure 3: Relation of the tooth decay with normal oxygen level in both.

\section{Bibliography}

1. Qadir MI and Javid A. "Awareness about Crohn's Disease in biotechnology students". Global Advanced Research Journal of Medicine and Medical Sciences 7.3 (2018): 62-64.

2. Qadir MI and Saleem A. "Awareness about ischemic heart disease in university biotechnology students". Global Advanced Research Journal of Medicine and Medical Sciences 7.3 (2018): 59-61.

3. Qadir MI and Ishfaq S. "Awareness about hypertension in biology students". International Journal of Pharmaceutical Research 7.2 (2018): 8-10.

4. Qadir MI and Mehwish. "Awareness about psoriasis disease". International Journal of Pharmaceutical Research 7.2 (2018): 17-18.

5. Qadir MI, Shahzad R. "Awareness about obesity in postgraduate students of biotechnology". International Journal of Pharmaceutical Research 7.2 (2018): 14-16.

6. Qadir MI and Rizvi M. "Awareness about thalassemia in post graduate students". MOJ Lymphology and Phlebology 2.1 (2018): 14-16.

7. Qadir MI and Ghalia BA. "Awareness survey about colorectal cancer in students of M. Phil Biotechnology at Bahauddin Zakariya University, Multan, Pakistan". Nov Appro in Can Study 1.3 (2018).

8. Qadir MI and Saba G. "Awareness about intestinal cancer in university student". Nov Appro in Can Study 1.3 (2018): NACS.000515.2018.

Volume 2 Issue 8 August 2019

(C) All rights are reserved by Muhammad Imran Qadir and Yasmeen Mureed. 